\title{
Optimal Placement of Dynamic Voltage Restorer in Distribution Systems for Voltage Improvement Using Particle Swarm Optimization
}

\author{
A. V. Sudhakara Reddy*, Dr.M.Damodar Reddy** N.Vinoda*** \\ *(Research Scholar, E.E.E, S V University, Tirupati-517502, India, Email: sreddy4svu@ gmail.com) \\ **(Professor, E.E.E, S V University, Tirupati-517502, India, Email: mdreddy999@ rediffmail.com) \\ ***(P.G.Student, E.E.E, S V University, Tirupati-517502, India, Email:vinoda.faith@ gmail.com)
}

\begin{abstract}
This paper deals with Dynamic Voltage Restorer (DVR) allocation in radial distribution systems by injecting series voltage. The DVR is used to inject both real and reactive powers into the system for voltage profile improvement and active and reactive power loss minimization. The objective of this paper is to identify the optimal location and series voltage of DVR using Particle Swarm Optimization (PSO) algorithm. The proposed method is tested on standard IEEE 33-bus system and the results are presented.
\end{abstract}

Keywords: Distribution system, DVR, Particle Swarm Optimization, series voltage, voltage profiles.

\section{INTRODUCTION}

In distribution systems the major concern is a power quality problem. Due to the radial nature of the distribution system, the voltage regulation at load end becomes poor. Voltage regulation is done by series voltage regulators and shunt capacitors. The various methods available for voltage regulation are shunt capacitor placement [1-2], integration of distributed generation (DG) [3], the latest advancement is distribution FACTS (DFACTS) also called as Custom Power Devices (CPD). Traditionally, DFACTS devices are used in the power quality improvement.

In [4], the optimal allocation of distribution static compensator (DSTATCOM) is carried out to mitigate network power loss and to improve node voltage magnitude. In [5], the modeling of DVR for voltage correction and the performance of the device under different voltage sags condition is presented. Voltage quality improvement by using Dynamic Voltage Restorer (DVR) and Distribution Static Synchronous Compensator (D-STATCOM) are reported in [6]. Modeling of Series Static Voltage Restorer (SSVR) in load flow calculations for steady state voltage improvement is explained in [7]. Network reconfiguration technique [8] is also used to reduce the losses in radial distribution systems. Many load flow methods developed for radial distribution system [9-12].

Almost all of the models reported till now for DVR have been utilized for two bus system consisting of sensitive load and the source. Effects of DVR modeling on compensation of power quality problems of sensitive loads have been considered. However the effects of DVR on a large distribution system and other loads have not been considered. In this paper, the effect of DVR on large distribution system is considered for voltage improvement and loss reduction. The effect of the DVR is analyzed in the steady state condition. Suitable modifications are made to the load flow program in order to improve the voltage of desired node to 1 p.u in steady state condition. The optimization technique known as PSO [13-14], proposed by Dr. Eberhart and Dr. Kennedy is used to obtain optimum series voltage.

\section{RADIAL DISTRIBUTION SYSTEM LOAD FLOW}

Load flow analysis is essential for the analysis of the distribution system in steady state, to investigate the issues related to planning, design and the operation and control. There are many load flow methods available in the literature. In this paper, a load flow method based on BIBC and BCBV method [11] is used. Most of the distribution systems are radial systems fed at a single point and system has radial nature as shown in Fig.1.

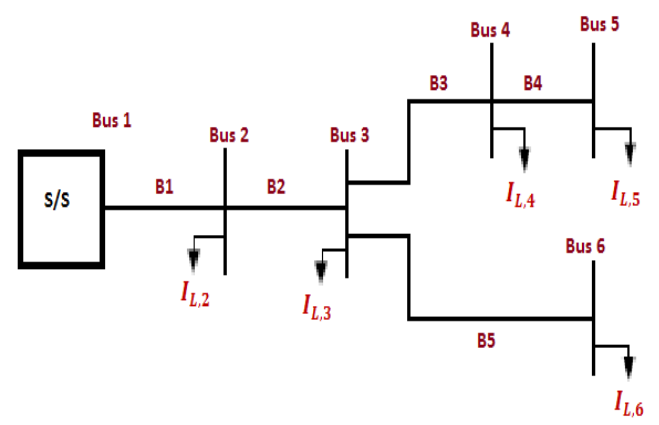

Fig.1. Simple 6 bus radial distribution system 
The proposed load flow algorithm requires formation of Bus Injection to Branch Current (BIBC) matrix and Branch Current to Bus Voltage (BCBV) matrix.

At bus $i$ the complex power at load $S_{L i}$ is given by

$S_{L i}=\left(P_{L i}+j Q_{L i}\right)$

Where $\mathrm{i}=2 \ldots . \mathrm{N}$

And the corresponding load current is given by

$I_{L}=\left(\frac{P_{L i}+j Q_{L i}}{V_{i}{ }^{k}}\right)^{*}$

Where $\mathrm{Si}$, is the complex power at $\mathrm{i}^{\text {th }}$ bus,

$P_{L i}$ is the real power at $\mathrm{i}^{\text {th }}$ bus

$Q_{L i}$, is the reactive power at $\mathrm{i}^{\text {th }}$ bus

$V_{i k}$ is the bus voltage at $\mathrm{k}^{\text {th }}$ iteration for $\mathrm{i}^{\text {th }}$ bus;

$\mathrm{N}=$ number of buses; $I_{L}$-load current.

The branch currents can be written as

$$
\left[I_{B}\right]=[B I B C] \quad\left[I_{L}\right]
$$

The relation between branch current and bus voltages is given by

$$
[\Delta V]=[B C B V] \quad\left[I_{B}\right]
$$

The receiving end voltages can be premeditated by forward sweeping across the line by subtracting the line section drop from the sending end voltages of the line section.

$$
V_{r}(i)=V_{s}(i)-I_{B}(i) * Z_{s}(i)
$$

Thus, we obtain the voltage magnitude and phase angle, which completes the load flow. The total real and reactive power losses in a distribution system can be written as

$$
\begin{aligned}
P_{\text {Loss }} & =\sum_{p=1}^{b} I_{B p}^{2} R_{p} \\
Q_{\text {Loss }} & =\sum_{p=1}^{b} I_{B p}^{2} X_{p}
\end{aligned}
$$

Where $b$ is the number of branches; $R_{p}$ is the resistance and $I_{B p}$ is the branch current of $\mathrm{p}^{\text {th }}$ branch of original network.

\section{DYNAMIC VOLTAGE RESTORER}

Dynamic Voltage Restorer (DVR) is a series device which is used to inject a series voltage to the network to improve the voltage profile. The Single Line Diagram of two buses of a radial distribution System with consideration of the DVR is as shown in Fig.2.

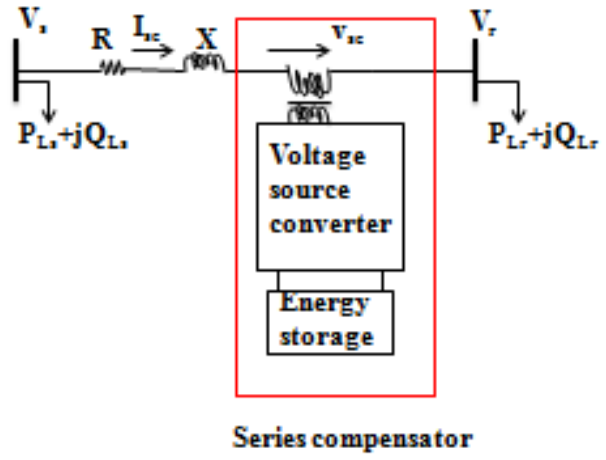

Fig.2. Single Line Diagram of Two Buses of a Distribution System with Consideration of DVR The voltage source converter of DVR injects the series voltage $\left(V_{s e}\right)$ in the branch to improve the voltage at the receiving end bus in such a way that the receiving end voltage $\left(V_{r} \operatorname{or} V_{L}\right)$ is maintained at a desired value (1p.u.) From fig 1, if the DVR is placed in the branch B2, then the receiving end bus 3 is maintained at 1 p.u. The phasor diagram in Fig.3

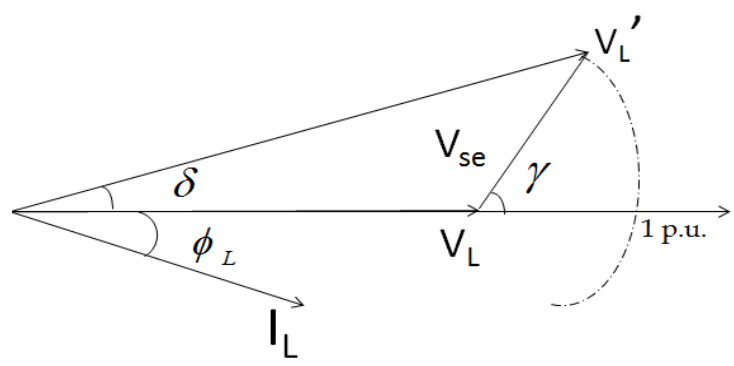

Fig3. Phasor diagram after including Vse

From the above phasor diagram given in Fig. 3 the new load bus voltage given in generalized form is

$V_{r}^{\prime} \angle \delta=V_{r}+V_{s e} \angle \gamma$

Where $V_{r}^{\prime} \square$ magnitude of receiving end bus voltage $V_{s e} \square$ Series injected voltage

$\delta \square$ Displacement angle between $V_{r}$ and $V_{r}^{\prime}$

$\gamma \square$ Series injected voltage angle with respect to receiving end load voltage $\left(V_{r}\right)$ angle.

Since DVR injects both active and reactive power into the system, the series power is given as follows:

$$
S_{D V R}=V_{s e} \cdot\left(I_{B}\right)^{*}
$$

Where $S_{D V R} \square$ complex power rating of DVR

$V_{s e} \square$ Series voltage injected by DVR

$I_{B} \square \quad$ Branch current in which DVR injects the series voltage 


\section{PARTICLE SWARM} OPTIMIZATION METHOD

Particle swarm optimization (PSO) method is a population based evolutionary computation technique developed by Dr. Eberhart and Dr. Kennedy in 1995, inspired by social behavior of bird flocking or fish schooling. The particle swarm concept originated as a simulation of a simplified social system, and has been found to be robust in solving continuous linear and nonlinear optimization problems. The PSO technique can generate highquality solutions within shorter calculation time and have more stable convergence characteristic than other stochastic methods.

Algorithm to find optimum values of series injected voltage using PSO technique

Step 1: Initialize the number of particles, maximum iterations, dimension, minimum and maximum series voltage limits and minimum and maximum velocity of the particles within the limits.

Step 2: Generate the particles and velocities randomly within the limits.

Step 3: Run the load flow by adding the series voltage in the branch as given in the equation (7). The voltage constraint imposed is the voltage at the optimal location should not exceed 1 p.u.

Find the fitness function using equation (5)

Step 4: pbest values for all the particles are obtained from the fitness values and the best value among all the particle best values (gbest) is identified.

Step 5: gbest and average fitness values are calculated.

Step 6: Iteration count is set to one.

Step 7: For all the particles, calculate the new velocities using equation

$V_{(m, n)}^{t+1}=k *\left(w * V_{(m, n)}^{t}+c_{1}\right.$ rand $_{1}\left(\mathrm{pbest}_{(m, n)}^{t}-\mathrm{X}_{(m, n)}^{t}\right)+c_{2}$ rand $\left(\right.$ gbest $\left.\left._{(1, n)}^{t}-\mathrm{X}_{(m, n)}^{t}\right)\right)$

Where $K=-0.7298$ is the constriction factor[13]; $\omega$ is the inertia weight given by

$w=w_{\text {max }}-\left(\frac{w_{\text {max }}-w_{\text {min }}}{T}\right) * t$

$C_{1}=C_{2}=2.05$ are acceleration constants.

$\operatorname{rand}_{1}, \operatorname{rand}_{2}$ are the random numbers

$V_{m n}^{\text {iter }}$ is velocity of $\mathrm{m}^{\text {th }}$ particle in $\mathrm{n}^{\text {th }}$ dimension; $\mathrm{X}_{m n}^{i t e r}$ is the position of $\mathrm{m}^{\text {th }}$ particle in $\mathrm{n}^{\text {th }}$ dimension; pbest $_{m n}^{\text {iter }}$ is the pbest particle $\mathrm{m}, \mathrm{n} ;$ gbest $_{m n}^{\text {iter }}$ is the gbest particle $\mathrm{m}, \mathrm{n}$.

$w$ is an adjustable parameter between

$w_{\text {max }}=0.9$ and $w_{\text {min }}=0.4$

$t=$ current iteration number

$T=$ maximum number of iterations
Step 8: Update the position of each particle as given in equation (11)

$$
\mathrm{X}_{(m, n)}^{t+1}=\mathrm{X}_{(m, n)}^{t}+V_{(m, n)}^{t+1}
$$

Step 9: New fitness functions are calculated for the new positions of all the particles. Update the pbest from equation (12):

$P_{\text {best }, t}^{t+1}= \begin{cases}P_{\text {best } t, t}^{t} & \text { if } f\left(x_{i}^{t+1}\right)>P_{\text {best }, i}^{t} \\ x_{i}^{t+1} & \text { if } f\left(x_{i}^{t+1}\right) \leq P_{\text {best }, i}^{t}\end{cases}$

Update the gbest from the latest pbest

Step 10: The iteration count is incremented and if the iteration count is not reached to max then go to step 7.

Step 11: gbest particle gives the optimal series voltage values and the results are printed.

\section{RESULTS}

The standard IEEE 33-bus radial distribution system is used to examine the applicability of DVR and illustrate the proposed approach.

Results of 33-bus system

The proposed algorithm is applied to 33bus system [9]. The system has real load of $3715 \mathrm{~kW}$ and and reactive load of $2300 \mathrm{kVAr}$. Table 1 shows the voltage profiles. Table 2 shows the results for 33-bus system. Table 3 shows the results for DVR Location, Series injected voltage, Real power injected, Reactive power injected, Power loss, Loss reduction and No. of nodes with under voltage problem for a 33 bus distribution system.

Table 1: Voltage profiles of 33 bus system without and with DVR

\begin{tabular}{|c|c|c|c|c|c|}
\hline \multirow[b]{2}{*}{$\begin{array}{c}\text { Bus } \\
\text { no }\end{array}$} & \multicolumn{2}{|c|}{ Voltage in p.u } & \multirow[b]{2}{*}{$\begin{array}{c}\text { Bus } \\
\text { no }\end{array}$} & \multicolumn{2}{|c|}{ Voltage in p.u } \\
\hline & $\begin{array}{c}\text { Without } \\
\text { DVR }\end{array}$ & $\begin{array}{l}\text { With } \\
\text { DVR }\end{array}$ & & $\begin{array}{c}\text { Without } \\
\text { DVR }\end{array}$ & $\begin{array}{l}\text { With } \\
\text { DVR }\end{array}$ \\
\hline 1 & 1.0000 & 1 & 18 & 0.9131 & 0.9654 \\
\hline 2 & 0.9970 & 0.9971 & 19 & 0.9965 & 0.9966 \\
\hline 3 & 0.9829 & 0.9834 & 20 & 0.9929 & 0.9930 \\
\hline 4 & 0.9755 & 0.9763 & 21 & 0.9922 & 0.9923 \\
\hline 5 & 0.9681 & 0.9692 & 22 & 0.9916 & 0.9917 \\
\hline 6 & 0.9497 & 1 & 23 & 0.9794 & 0.9799 \\
\hline 7 & 0.9462 & 0.9967 & 24 & 0.9727 & 0.9732 \\
\hline 8 & 0.9413 & 0.9921 & 25 & 0.9694 & 0.9699 \\
\hline 9 & 0.9351 & 0.9862 & 26 & 0.9477 & 0.9982 \\
\hline 10 & 0.9292 & 0.9807 & 27 & 0.9452 & 0.9957 \\
\hline 11 & 0.9284 & 0.9799 & 28 & 0.9337 & 0.9849 \\
\hline 12 & 0.9269 & 0.9784 & 29 & 0.9255 & 0.9771 \\
\hline 13 & 0.9208 & 0.9727 & 30 & 0.9220 & 0.9738 \\
\hline 14 & 0.9185 & 0.9705 & 31 & 0.9178 & 0.9698 \\
\hline 15 & 0.9171 & 0.9692 & 32 & 0.9169 & 0.9690 \\
\hline 16 & 0.9157 & 0.9679 & 33 & 0.9166 & 0.9687 \\
\hline 17 & 0.9137 & 0.9660 & & & \\
\hline
\end{tabular}


A. V. Sudhakara Reddy.et.al. Int. Journal of Engineering Research and Application www.ijera.com ISSN : 2248-9622, Vol. 7, Issue 3, ( Part-1) March 2017, pp.29-33

Table 2: Results of 33 bus system

\begin{tabular}{|c|c|c|c|c|c|}
\hline Description & $\begin{array}{c}\text { Real power } \\
\text { loss (kW) }\end{array}$ & $\begin{array}{c}\text { Reactive power } \\
\text { loss (kVAr) }\end{array}$ & $\begin{array}{c}\text { Minimum } \\
\text { voltage (p.u.) }\end{array}$ & $\begin{array}{c}\text { No. of Buses with } \\
\text { Under voltage }\end{array}$ & $\begin{array}{c}\text { Rating of } \\
\text { DVR }\end{array}$ \\
\hline $\begin{array}{c}\text { Before DVR } \\
\text { installation }\end{array}$ & 202.6771 & 135.1410 & $\begin{array}{c}0.9131 \\
@ \text { bus } 18\end{array}$ & 21 & 0 \\
\hline $\begin{array}{c}\text { After } \\
\text { DVR } \\
\text { installation }\end{array}$ & 185.2856 & 123.2805 & $\begin{array}{c}0.9654 \\
\text { @bus18 }\end{array}$ & 0 & $124.47 \mathrm{kVA}$ \\
\hline
\end{tabular}

Table 3: DVR Location, Series injected voltage, Real power injected, Reactive power injected, Power loss,

Loss reduction and No. of nodes with under voltage problem for standard IEEE 33-bus distribution system

\begin{tabular}{|c|c|c|c|c|c|c|c|c|}
\hline \multirow[b]{2}{*}{$\begin{array}{l}\text { DVR } \\
\text { Location } \\
\text { (branch) }\end{array}$} & \multirow[b]{2}{*}{$\begin{array}{l}\text { Series injected } \\
\text { voltage (p.u) }\end{array}$} & \multirow{2}{*}{$\begin{array}{c}\text { Real } \\
\text { power } \\
\text { injected } \\
(\mathrm{kW})\end{array}$} & \multirow{2}{*}{$\begin{array}{l}\text { Reactive } \\
\text { power } \\
\text { injected } \\
\text { (kVAr) }\end{array}$} & \multicolumn{2}{|c|}{ Power Loss } & \multicolumn{2}{|c|}{ Loss Reduction } & \multirow{2}{*}{$\begin{array}{l}\text { No. of } \\
\text { nodes } \\
\text { with } \\
\text { under } \\
\text { voltage } \\
\text { problem }\end{array}$} \\
\hline & & & & $\begin{array}{l}\text { Real } \\
(\mathrm{kW})\end{array}$ & $\begin{array}{c}\text { Reactive } \\
\text { (kVAr) }\end{array}$ & $\begin{array}{l}\text { Real } \\
(\mathrm{kW})\end{array}$ & $\begin{array}{c}\text { Reactive } \\
\text { (kVAr) }\end{array}$ & \\
\hline 1 & $0.0026+\mathrm{j} 0.0270$ & 11.55 & 7.179 & 201.2971 & 134.2188 & 1.38 & 0.9222 & 19 \\
\hline 2 & $0.0168+\mathrm{j} 0.0000$ & 56.7967 & 36.3834 & 195.1382 & 130.1075 & 7.5389 & 5.0335 & 14 \\
\hline 3 & $0.0240+\mathrm{j} 0.0000$ & 56.2369 & 39.9454 & 193.358 & 128.8263 & 9.3191 & 6.3147 & 10 \\
\hline 4 & $0.0310+\mathrm{j} 0.0000$ & 68.4093 & 48.7682 & 190.9854 & 127.1863 & 11.6917 & 7.9547 & 3 \\
\hline 5 & $0.0480+\mathrm{j} 0.0000$ & 101.0600 & 72.6630 & 185.2856 & 123.2805 & 17.3915 & 11.8605 & 0 \\
\hline 6 & $0.0433+\mathrm{j} 0.1321$ & 0.0000 & 168.0000 & 191.5033 & 127.5493 & 11.1738 & 7.5917 & 8 \\
\hline 7 & $0.0455+\mathrm{j} 0.1501$ & 0.0000 & 153.8000 & 192.0447 & 127.9254 & 10.6324 & 7.2156 & 9 \\
\hline 8 & $0.0473+\mathrm{j} 0.1769$ & 0.0000 & 137.8100 & 192.7451 & 128.3799 & 9.932 & 6.7611 & 10 \\
\hline 9 & $0.0504+\mathrm{j} 0.1904$ & 0.0000 & 135.1200 & 192.7968 & 128.4073 & 9.8803 & 6.7337 & 11 \\
\hline 10 & $0.0524+\mathrm{j} 0.1853$ & 0.0000 & 119.9300 & 193.7173 & 129.0231 & 8.9598 & 6.1179 & 12 \\
\hline 11 & $0.0508+\mathrm{j} 0.2016$ & 0.0000 & 118.1900 & 193.8112 & 129.0839 & 8.8659 & 6.0571 & 13 \\
\hline 12 & $0.0478+\mathrm{j} 0.2411$ & 0.0000 & 122.0100 & 193.5202 & 128.8801 & 9.1569 & 6.2609 & 14 \\
\hline 13 & $0.0390+\mathrm{j} 0.2833$ & 0.0018 & 121.9300 & 193.5172 & 128.8754 & 9.1599 & 6.2656 & 15 \\
\hline 14 & $0.0000+\mathrm{j} 0.3978$ & 8.3202 & 113.1700 & 192.9778 & 128.4849 & 9.6993 & 6.6561 & 16 \\
\hline 15 & $0.0000+\mathrm{j} 0.4030$ & 3.3758 & 90.6530 & 195.1905 & 129.9944 & 7.4866 & 5.1466 & 17 \\
\hline 16 & $0.0000+\mathrm{j} 0.4093$ & 1.8428 & 66.1198 & 197.1607 & 131.3345 & 5.5164 & 3.8065 & 18 \\
\hline 17 & $0.0244+\mathrm{j} 0.3525$ & 0.0004 & 34.8009 & 199.8116 & 133.1549 & 2.8655 & 1.9861 & 19 \\
\hline 18 & $0.0035+\mathrm{j} 0.0079$ & 0.0000 & 3.4196 & 202.659 & 135.1281 & 0.0181 & 0.0129 & 21 \\
\hline 19 & $0.0069+\mathrm{j} 0.0162$ & 0.0000 & 5.2031 & 202.6462 & 135.1183 & 0.0309 & 0.0227 & 21 \\
\hline 20 & $0.0076+\mathrm{j} 0.0179$ & 0.0000 & 3.8252 & 202.6536 & 135.1233 & 0.0235 & 0.0177 & 21 \\
\hline 21 & $0.0082+\mathrm{j} 0.0194$ & 0.0000 & 2.0767 & 202.6639 & 135.1309 & 0.0132 & 0.0101 & 21 \\
\hline 22 & $0.0194+\mathrm{j} 0.0451$ & 0.0000 & 51.0598 & 201.3734 & 134.3725 & 1.3037 & 0.7685 & 21 \\
\hline 23 & $0.0250+\mathrm{j} 0.0617$ & 0.0000 & 62.0383 & 201.0736 & 134.1913 & 1.6035 & 0.9497 & 21 \\
\hline 24 & $0.0278+\mathrm{j} 0.0705$ & 0.0000 & 35.2720 & 201.7125 & 134.5614 & 0.9646 & 0.5796 & 21 \\
\hline 25 & $0.0509+\mathrm{j} 0.0000$ & 48.2397 & 49.2485 & 192.6181 & 128.3644 & 10.059 & 6.7766 & 12 \\
\hline 26 & $0.0533+\mathrm{j} 0.0000$ & 47.2082 & 50.1403 & 192.5075 & 128.2738 & 10.1696 & 6.8672 & 13 \\
\hline 27 & $0.0638+\mathrm{j} 0.0000$ & 52.0538 & 57.7704 & 191.1046 & 127.3048 & 11.5725 & 7.8362 & 14 \\
\hline 28 & $0.0713+\mathrm{j} 0.0000$ & 53.4372 & 62.6472 & 190.4022 & 126.8182 & 12.2749 & 8.3228 & 15 \\
\hline 29 & $0.0748+\mathrm{j} 0.0000$ & 46.9229 & 60.3763 & 191.253 & 127.3901 & 11.4241 & 7.7509 & 16 \\
\hline 30 & $0.0537+\mathrm{j} 0.2198$ & 0.0000 & 106.3300 & 192.4493 & 128.1172 & 10.2278 & 7.0238 & 17 \\
\hline 31 & $0.0567+\mathrm{j} 0.2144$ & 0.0000 & 67.4496 & 196.0367 & 130.5669 & 6.6404 & 4.5741 & 18 \\
\hline 32 & $0.0702+\mathrm{j} 0.1538$ & 0.0000 & 12.1930 & 201.4373 & 134.2829 & 1.2398 & 0.8581 & 20 \\
\hline
\end{tabular}


When DVR is placed in branch 5 (6th node) the number of nodes with under voltage problem is zero. The real and reactive power losses with DVR in branch 5 are $185.2856 \mathrm{~kW}$ and 123.2805 kVAr respectively. DVR placement in the branches 18 to 24 at (19 to 25 nodes) does not result in much significant improvement in voltage \& loss reduction.

\section{CONCLUSION}

The effect of the DVR is considered by injecting both real and reactive power. The optimal location is the location at which minimum losses are obtained. The optimum series voltage is obtained by using PSO method. The results show that there is considerable improvement in voltage profile and reduction in losses.

\section{REFERENCES}

[1] M. Damodar Reddy and V.C. Veera Reddy. "A two-stage methodology for capacitor placement for the reconfigured network". Indian Journal of engineering and materials sciences, vol 17, 2010 pp. 105-112.

[2] M. Damodar Reddy and V.C. Veera Reddy. "Capacitor placement using fuzzy and particle swarm optimization method for maximum annual savings". ARPN Journal of Engineering and Applied Sciences. 3(3), Jan- 2008.

[3] Chiranjit Mondal "Distributed Generation Allocation For Power Loss Minimization And Voltage Improvement Of Radial Distribution Systems Using Different Techniques". International Journal of Research in Engineering \& Advanced Technology, 3(2), April-May, 2015.

[4] S. Jazebi, S. H. Hosseini, and B. Vahidi, "DSTATCOM allocation in distribution networks considering reconfiguration using differential evolution algorithm," Energy Conversion and Manageme, vol. 52, 2011, 2777-2783.

[5] Ahmed M. Saeed, Shady H.E. Abdel aleem, Ahmed M. Ibrahim, Murat E. Balci, Essam E.A. El-Zahab, "Power conditioning using dynamic voltage restorers under different voltage sag types" IEEE, 2015.

[6] D.Smriti, "Comparison of DVR and DSTATCOM for Voltage Quality Improvement", International Journal of Emerging Technology and Advanced Engineering, vol 4, issue. 10, Oct 2014.

[7] M. Fotuhi-Firuzabad, H. A. Shayanfar, M. Hosseini, "Modeling of Series Static Voltage Restorer (SSVR) in Distribution Systems Load Flow", in IEEE, 2007, 310-315.
[8] A. V. Sudhakara Reddy, Prof. M. Damodar Reddy, "Optimization of distribution network reconfiguration using dragonfly algorithm", Journal of Electrical Engineering, Vol.16.4.30, pp.273-282, ISSN:1582-4594, Dec-2016.

[9] M.H.Haque. "Efficient load flow method for distribution systems with radial or meshed configuration". IEE Proc - Gener Transm Distrb 1996; 143 (1):33-38.

[10] J Ma , J Xu, S Wang, X Lin. "Calculation and analysis for line losses in distribution network", in IEEE, 2002, 2537-2541.

[11] S. Ghosh and D. Das, "Method for load-flow solution of radial distribution networks," IEE Proceedings - Generation, Transmission and Distribution, vol. 146, no. 6, 641, 1999.

[12] D.Das, D.P.Kothari and A.Kalam, "Simple and efficient method for load flow solution of Radial distribution networks", Electrical Power \& Energy Systems, vol.17, no.5, pp.335-346, 1995.

[13] A. V. Sudhakara Reddy, Prof. M. Damodar Reddy, "Optimization of network reconfiguration by using particle swarm optimization", IEEE, 2016.

[14] Y.Shi \& R.Eberhard "A modified particle swarm optimizer". In IEEE Conference of Evolutionary and Neural computing (pp. 6973), 1999.

\section{Author's Profile}

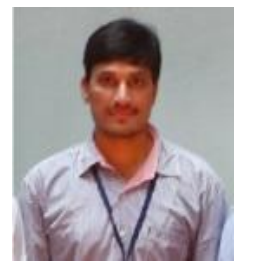

A. V. Sudhakara Reddy has 7 years of experience in teaching and research. Presently he is working as a Full-Time Research Scholar at S.V.University, Tirupati, India. His research area is Studies on power system optimization.

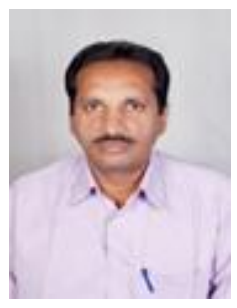

Prof. M. Damodar Reddy has 25 years of experience in teaching \& Research. Presently he is working as a Senior Professor at S.V.University, Tirupati, India. His Research area is Power system optimization \& Reactive power compensation.

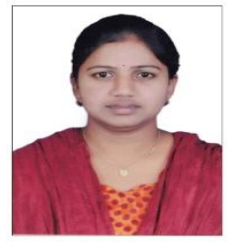

N.Vinoda is a M.Tech student in S.V.University College of Engineering, S.V.University, Tirupati, India. 